ORIGINAL RESEARCH

\title{
Predictive Value of Basal Exhaled Nitric Oxide and Carbon Monoxide for Acute Mountain Sickness
}

\author{
Haiyan You, PhD*; Xiaoxiao Li, PhD*; Tao Pei, PhD; Qingyuan Huang, MD; Fuyu Liu, MD; Yuqi Gao, MD \\ From the Departments of Health Service (Drs You, Li, and Pei), and Pathophysiology and High-Altitude Physiology (Drs Huang, Liu, and \\ Gao), College of High-Altitude Military Medicine, Third Military Medical University; and the Key Laboratory of High-Altitude Medicine \\ (Third Military Medical University), Ministry of Education and PLA (Drs You, Li, Pei, Huang, Liu, and Gao), Chongqing, P.R. China.
}

\begin{abstract}
Objective.-The purpose of this study was to examine the relationship between acute mountain sickness (AMS) and the fraction of exhaled nitric oxide $\left(\mathrm{FE}_{\mathrm{NO}}\right)$ and carbon monoxide $\left(\mathrm{FE}_{\mathrm{CO}}\right)$ before ascent to high altitude and to evaluate their predictive value for AMS.

Methods.-A total of 314 healthy young male recruits were voluntarily enrolled. Before ascent to an elevation of $4300 \mathrm{~m}$, their $\mathrm{FE}_{\mathrm{NO}}$ and $\mathrm{FE}_{\mathrm{CO}}$ values, demographic factors, drinking and smoking history, vital capacity, and forced vital capacity were obtained. The investigators followed the subjects in the first exposure week to obtain their Lake Louise Score (LLS) each day. Subjects with LLS > 4, headache, and at least 1 other symptom were diagnosed with AMS, and the highest LLS of each individual during 7 days was considered the final LLS score.

Results.-The AMS group had lower $\mathrm{FE}_{\mathrm{NO}}(P=.003)$ and $\mathrm{FE}_{\mathrm{CO}}(P<.001)$ values, and a lower smoking rate $(P<.001)$ than the non-AMS group. Mean $\mathrm{FE}_{\mathrm{NO}}$ and $\mathrm{FE}_{\mathrm{CO}}$ values were $11.03 \mathrm{ppb}(95 \%$ CI, 9.07 to 12.98 ) and $4.39 \mathrm{ppm}(95 \% \mathrm{CI}, 3.76$ to 5.02), respectively, in the AMS group, and $14.74 \mathrm{ppb}$ (95\% CI, 13.25 to 16.23$)$ and $6.10 \mathrm{ppm}(95 \% \mathrm{CI}, 5.49$ to 6.72$)$, respectively, in the non-AMS group $(P<.0001)$. Using linear regression, both $\mathrm{FE}_{\mathrm{NO}}$ and $\mathrm{FE}_{\mathrm{CO}}$ were found to be significantly associated with the group's maximal LLS. Using logistic regression, $\mathrm{FE}_{\mathrm{NO}}$ and $\mathrm{FE}_{\mathrm{CO}}$ were also found to be significantly associated with AMS.
\end{abstract}

Conclusions.-Basal $\mathrm{FE}_{\mathrm{NO}}$ and $\mathrm{FE}_{\mathrm{CO}}$ are significantly negatively correlated with AMS development. However, the gases have only modest predictive value for the development of AMS.

Key words: acute mountain sickness, susceptibility, exhaled nitric oxide, exhaled carbon monoxide

\section{Introduction}

Acute mountain sickness (AMS) is a common illness affecting people entering high altitudes, causing adverse health effects that seriously affect physical performance. In the field of high altitude medical research, the prediction of AMS susceptibility in individuals going to high altitudes is still a thriving area of study. Researchers have been looking for the factors to predict AMS. So far, data from studies on the factors to predict AMS are inconsistent. Some studies have shown that poor hypoxic ventilatory response, ${ }^{1,2}$ age $^{3-5}$ and body mass index $(\mathrm{BMI})^{5}$

\footnotetext{
*These authors contributed equally to this work.

Disclaimer: There are no conflicts of interest to disclose.

Corresponding author: Yuqi Gao, MD, Department of Health Service, College of High-Altitude Medicine, Third Military Medical University, 30 Gaotanyan Street, Shapingba District, Chongqing, China (e-mail: gaoy66@yahoo.com).
}

are associated with AMS development; however, other studies have indicated that these factors are not associated with AMS. ${ }^{6-10}$ Macinnis et $\mathrm{al}^{11}$ reviewed the genetics of altitude illness in 2010 and reported that no reliable genetic factors to predict AMS have yet been identified. In addition, the methods for measuring some factors cannot be adopted for a large population, as these methods are not noninvasive, simple, quick, convenient, and relatively low-cost. Thus, we are searching for some simple, quick, convenient, and relatively low-cost methods to predict AMS risk.

The pathophysiological mechanisms of AMS development are still unclear; however, it is reported that vascular constriction during hypoxia, especially cerebrovascular and pulmonary vascular constriction, plays a role in AMS. ${ }^{12}$ Nitric oxide (NO) is a gaseous signaling molecule with a large variety of physiological functions, 
including airway and vascular smooth muscle relaxation and the regulation of ventilation-perfusion matching. ${ }^{13}$ Nitric oxide is produced endogenously within the upper and lower respiratory tract and can be measured in exhaled gas. ${ }^{14}$ Studies have revealed that during hypoxic breathing, the exhaled NO from the respiratory tract of high altitude pulmonary edema (HAPE) -susceptible subjects was lower than that from the control subjects at both altitude and sea level and that a negative relationship existed between the exhaled $\mathrm{NO}$ and the pulmonary artery pressure. ${ }^{15}$ Exhaled NO is associated with AMS susceptibility during exposure to normobaric hypoxia. ${ }^{16}$ The defect in pulmonary endothelial cell and respiratory epithelial cell NO synthesis is one of the mechanisms contributing to exaggerated hypoxic pulmonary hypertension during shortterm high altitude exposure. ${ }^{17}$ These findings indicate that exhaled NO might be associated with AMS susceptibility during exposure to high altitude.

Smoking can cause hypoxia and is also associated with a decline in lung function. Some scholars have suggested that smoking is not significantly correlated with AMS, ${ }^{3,10,18}$ but others believe that it may be a risk factor for AMS. ${ }^{19}$ However, these conclusions cannot be effectively verified because of a lack of quantitative measurement of smoking behavior in these studies (the data were qualitative and collected by questionnaires) and an absence of effective measurement of the inhalation level, which is of great importance when evaluating exposure. Because of the great individual variations, the inhalation level may not be adequately evaluated by self-reported smoking behavior. The use of carbon monoxide (CO) monitors to quantify smoking has been reported, in which the level of exhaled $\mathrm{CO}$ has been widely used as an indication of smoking cessation. ${ }^{20,21}$ Carbon monoxide may also play an important role in the pathophysiology of airway diseases ${ }^{22}$ and hemoglobin survival, which may be potentially related to AMS. ${ }^{23}$ However, more precise monitoring is required to determine the relationship between the level of exhaled $\mathrm{CO}$ and AMS.

As gaseous signaling molecules, ${ }^{24,25} \mathrm{NO}$ and $\mathrm{CO}$ have the characteristics of continuous production, rapid delivery, and rapid diffusion; thus, they can be detected by exhaled gas tests. ${ }^{14,26}$ In practice, measuring the fraction of exhaled $\mathrm{NO}$ and $\mathrm{CO}\left(\mathrm{FE}_{\mathrm{NO}}\right.$ and $\left.\mathrm{FE}_{\mathrm{CO}}\right)$ is noninvasive, simple, repeatable, quick, convenient, and relatively lowcost. As a result, these fractions have been increasingly used in clinical diagnosis. Therefore, we attempt to validate the hypothesis that $\mathrm{FE}_{\mathrm{NO}}$ and $\mathrm{FE}_{\mathrm{CO}}$ before ascent to high altitude are associated with AMS and to assess the predictive value of the 2 gases for AMS susceptibility.

\section{Materials and Methods}

\section{ETHICS STATEMENT}

This study was approved by the Ethical Review Board of the Third Military Medical University, Chongqing, China. There was no interaction between the study researchers and the individuals whose data were accessed. Personal information was removed from all data before retrieval and analysis.

\section{SUBJECTS AND SETTINGS}

Recruits of a highland troop in West China were selected as the study population. They were receiving training at a military base at an altitude of $1350 \mathrm{~m}$. A total of 391 healthy male servicemen were voluntarily enrolled. Before the questionnaire and physical examination, all recruits attended a meeting held at the base to clarify the purpose, method, and significance of the study. Individuals interested in participating in the study signed a consent form. The consent form required the participant's signature only and excluded other personal identifying information.

One investigator then performed an examination to obtain basic demographic data, ascent history, and drinking and smoking histories. Their health records were obtained from the troop's health service authority. An individual was excluded if any of the following was found: 1) previous ascent to an altitude $>2900 \mathrm{~m}, 2$ ) being born and raised in a region with an altitude $>2500$ $\mathrm{m}, 3$ ) other acute diseases during the study period, including cold and diarrhea, 4) asthma or other pulmonary diseases, 5) any other severe chronic diseases, or 6) incomplete study information.

Variables of age and BMI (calculated as weight in kilograms divided by stature in meters squared) extracted from the health record were controlled. Drinking behaviors were surveyed by questionnaire and classified into 2 categories: 1 for current drinking and 0 for no current drinking. Smoking behaviors were also surveyed by questionnaire and classified into 2 categories: 1 for current smoking and 0 for no current smoking. If smoking currently, the subject needed to provide the duration of his smoking history and the amount of his weekly consumption. Vital capacity (VC) and forced vital capacity (FVC) were tested with a pulmonary function meter (AS-505, Minato Medical Science Corp, Osaka, Japan), according to the manufacturer's instructions. Smoking and drinking were also prohibited during the operation. 


\section{FRACTION EXHALED NITRIC OXIDE AND CARBON MONOXIDE TESTS}

The $\mathrm{FE}_{\mathrm{NO}}$ and $\mathrm{FE}_{\mathrm{CO}}$ were measured using a portable NObreath and Micro $^{+}$Smokerlyzer monitor (Bedfont Scientific Ltd, Maidstone, Kent, UK). The lower and upper limits of detection (LOD) of NObreath and of the Micro $^{+}$Smokerlyzer were 1 and $300 \mathrm{ppb}$ and 1 and 250 ppm, respectively. The calibration and measurement procedures were performed according to the device operating manuals consistent with the European Respiratory Society (ERS) and American Thoracic Society (ATS) standards. ${ }^{27}$

Tests for $\mathrm{FE}_{\mathrm{NO}}$ and $\mathrm{FE}_{\mathrm{CO}}$ were conducted in $\mathrm{CO}$ - and NO-free clinic rooms before subjects' ascent to high altitude, and the ambient air was tested by the devices in advance. Before formal testing, all observers were well trained, and all subjects were instructed in detail on how to use the devices and asked to avoid smoking for half a day. For the $\mathrm{FE}_{\mathrm{NO}}$ test, an observer attached a mouthpiece to the device and confirmed that all connections were firm and all settings correct. The subject inhaled ambient air to near total lung capacity (not through the mouthpiece) and exhaled for 20 seconds at a constant flow rate through the mouthpiece into the device until a beep was heard; the device recorded and displayed the result in parts per billion. For the $\mathrm{FE}_{\mathrm{CO}}$ test, subjects inhaled as deeply as possible and held their breath for 20 seconds, then exhaled slowly and gently into the mouthpiece until being unable to exhale further; the device recorded and displayed the result in parts per million. A subject with an $\mathrm{FE}_{\mathrm{CO}}$ value $>6$ was considered to be smoking. After each test was completed, the mouthpieces were replaced. There was a 15 -minute rest interval between each 30-person test to reset the sensors.

\section{ACUTE MOUNTAIN SICKNESS DIAGNOSIS}

Subjects were divided into 3 groups. The groups were deployed to the destination at an altitude of $4300 \mathrm{~m}$ one after another by bus from the training base in April 2010. Each group traveled together with 2 observers on the 1080-km journey, in which the average altitude was $4254 \pm 988.88 \mathrm{~m}$ (standard deviation), as shown in Figure 1. During the 4-day journey, they traveled during the day and rested for 1 night at each army service station.

The AMS diagnoses were based on the Lake Louise score (LLS), an international standard scoring system for AMS. ${ }^{28}$ Before ascending, all investigators and subjects had become familiar with the LLS. The symptom investigations were performed every day after arrival at each army service station at 9 PM. The subjects were permitted

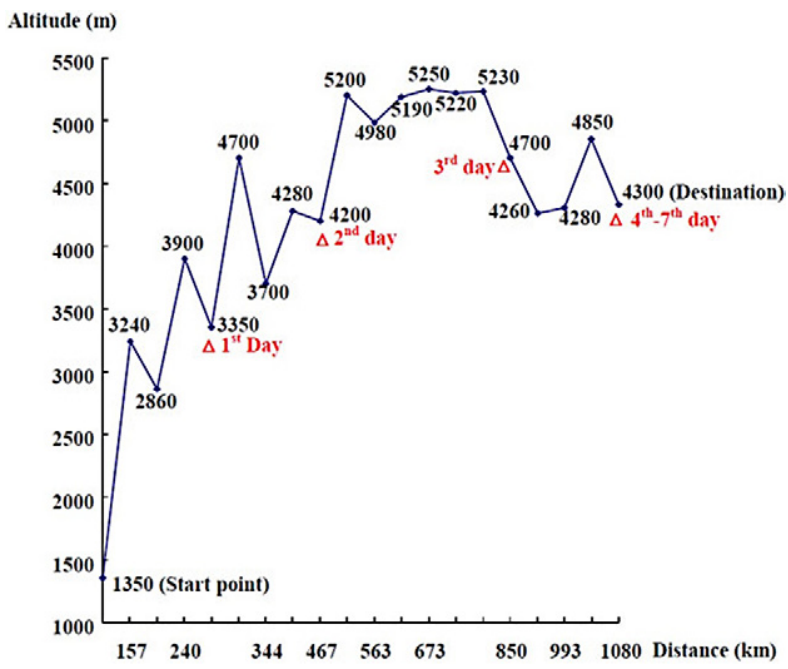

Figure 1. Changes in altitude and distance during the journey $(\Delta$ indicates the sleeping altitude each day).

a rest of 2 hours before investigations and then asked to complete an LLS self-report questionnaire (Questions 1-5: headache, gastrointestinal symptoms, fatigue and/or weakness, dizziness/lightheadedness, and sleeping difficulty) in a quiet environment. Clinical signs and symptoms (Questions 6-8: change in mental status, ataxia, and peripheral edema) were determined by observers. Each person's 4-day score during the journey was recorded. After arrival at the destination, the investigation continued for an additional 3 days. Thus, a 7-day record of the LLSs for subjects was obtained. If an individual's LLS was 5 or more (Questions 1-8) on any day, with headache and at least 1 other symptom (from Questions 1-5), that subject was considered to be suffering from AMS on that day. ${ }^{28,29}$ We further selected the highest LLS of each individual to build a max-LLS subset, and during 7 days the highest LLS of each individual was considered the final LLS value. Subjects were then divided into AMS (5 or greater) and non-AMS $(<5)$ groups; the non-AMS group was further divided into 2 subgroups: 0 for no symptom and 1-4 for a few symptoms but no AMS present.

\section{STATISTICAL ANALYSIS}

The data were analyzed using SPSS 13.0 software (Chicago, IL) and a probability value of less than .05 was considered statistically significant in all analyses. Before analyses, all data were reviewed by the principal investigator for completeness.

We first performed descriptive statistics: 1) the LLSs were classified into 3 groups (0 point, 1-4 points, and 5 or more points), and the number of each category and 
percentage on each day were computed; 2) the number and percentage of smoking and drinking behaviors in AMS diagnosis categories were computed; 3 ) the mean and standard deviation of each continuous variable (ie, age, BMI, VC, FVC, $\mathrm{FE}_{\mathrm{NO}}, \mathrm{FE}_{\mathrm{CO}}$, daily LLS, and maxLLS) were calculated; 4) a chart of altitude change with distance during the journey was also drawn.

A Student's $t$ test was performed to determine the mean difference in each continuous variable between the AMS and non-AMS groups, and a $\chi^{2}$ test was performed to determine drinking and smoking behavior differences between these 2 groups. Pearson's correlation test for continuous variables and Spearman's correlation test for categorical variables were used to evaluate relationships between age, BMI, VC, FVC, smoking, drinking, $\mathrm{FE}_{\mathrm{NO}}$, $\mathrm{FE}_{\mathrm{CO}}$, daily LLS, and max-LLS. To examine the normality of each continuous variable, a Kolmogorov-Smirnov test was performed, and log transformations were used for nonnormal variables.

Next, to test the relationship between the AMS score and $\mathrm{FE}_{\mathrm{NO}}$ and $\mathrm{FE}_{\mathrm{CO}}$, we performed linear regression analyses using daily LLS and max-LLS as dependent variables and $\mathrm{FE}_{\mathrm{NO}}$ and $\mathrm{FE}_{\mathrm{CO}}$ as independent variables and controlling age, BMI, VC, and FVC. We constructed separate models to test $\mathrm{FE}_{\mathrm{NO}}$ and $\mathrm{FE}_{\mathrm{CO}}$ (16 separate models in total) and then put all variables into a multivariate linear model (8 integrated models in total). Categorical variables were transformed into dummy ones for analysis. The fulfillment of collinearity absence was tested by calculating variance inflation factor (VIF).

Finally, a logistic regression was used to test the predictive values of $\mathrm{FE}_{\mathrm{NO}}$ and $\mathrm{FE}_{\mathrm{CO}}$ for $\mathrm{AMS}$ susceptibility, in which AMS diagnosis was used as a dependent variable and the other processes were the same as in the linear models. The fulfillment of independence and collinearity were tested in the multiple models. The fit of the logistic regression models was evaluated by the HosmerLemeshow goodness-of-fit test. The discriminative power of the significant predictive factors was visualized using receiver operating characteristic (ROC) curves. The ROC curve analyses were conducted using Med Calc 11.6 software (MedCalc Software bvba, Broekstraat, Belgium), including calculation of the area under the curve (AUC) with 95\% CI, comparison of ROC curves, selection of the cutoff value, and calculation of sensitivity, specificity, positive predictive value, and negative predictive value.

\section{Results}

After filtering, 314 healthy servicemen remained in our study (mean age $\pm \mathrm{SD}, 20.18, \pm 1.73$ years; mean stature $\pm \mathrm{SD}, 171.74, \pm 6.49 \mathrm{~cm}$; mean weight $\pm \mathrm{SD}$, $63.27, \pm 7.10 \mathrm{~kg})$.

The total distance of the journey was $1080 \mathrm{~km}$, in which the highest altitude encountered was $5250 \mathrm{~m}$ and the highest sleeping altitude was $4700 \mathrm{~m}$ (day 3; Figure 1). The data indicated that AMS developed and increased when the subjects entered the highland. The peak appeared on day 3, after which the incidence decreased. On day 7 , AMS was nearly absent in the population. There was no case of HAPE or high altitude cerebral edema.

Both the highest LLS and the largest number of individuals with an LLS $>4$ appeared on day 3, when the average LLS was $3.87 \pm 3.37$ and 119 individuals had an LLS $>4$ (37.9\%; Table 1). According to our criteria, 119 (37.9\%) of the 314 subjects (equal to the total number of subjects having an LLS $>4$ on day 3 ) investigated on the total journey were diagnosed with AMS, with the highest LLS reported as 21.

The mean and standard deviation of each continuous variable in the AMS and non-AMS groups are shown in Table 2. Age, BMI, and FVC did not differ between the groups. However, $\mathrm{FE}_{\mathrm{NO}}$ and $\mathrm{FE}_{\mathrm{CO}}$ significantly differed between the non-AMS and AMS groups; the AMS group had lower $\mathrm{FE}_{\mathrm{NO}}$ and $\mathrm{FE}_{\mathrm{CO}}$ values. For $\mathrm{VC}$, the probability value of the Student's $t$ test was just below the level of significance $(P=.054)$. The results also showed that the 95\% CI for means of $\mathrm{FE}_{\mathrm{NO}}$ value ranged from 13.25 to 16.23 in the non-AMS group and from 9.07 to 12.98 in the AMS group; the $95 \% \mathrm{CI}$ for means of $\mathrm{FE}_{\mathrm{CO}}$ value ranged from 5.49 to 6.72 in the non-AMS group and from 3.76 to 5.02 in the AMS group. As shown in Table

Table 1. The number (percentage) of subjects in different Lake Louise Score categories on each day and the mean Lake Louise Score on each day $(n=314)^{a}$

\begin{tabular}{|c|c|c|c|c|}
\hline & \multicolumn{3}{|c|}{ LLS category } & \multirow[b]{2}{*}{$\begin{array}{c}\text { Mean } \\
L L S \pm S D\end{array}$} \\
\hline & $\begin{array}{c}0 \\
n(\%)\end{array}$ & $\begin{array}{c}1-4 \\
n(\%)\end{array}$ & $\begin{array}{c}>4 \\
n(\%)\end{array}$ & \\
\hline Day 1 & $42(13.4)$ & $253(80.6)$ & $19(6.1)$ & $1.73 \pm 1.34$ \\
\hline Day 2 & $47(15.0)$ & $235(74.8)$ & $32(10.2)$ & $2.19 \pm 1.59$ \\
\hline Day 3 & $65(20.7)$ & $127(40.4)$ & $119(37.9)$ & $3.87 \pm 3.37$ \\
\hline Day $4^{a}$ & $46(14.6)$ & $220(70.1)$ & $48(15.3)$ & $2.46 \pm 1.81$ \\
\hline Day $5^{a}$ & $77(24.5)$ & $216(68.8)$ & $21(6.7)$ & $1.81 \pm 1.71$ \\
\hline Day $6^{a}$ & $90(28.7)$ & $220(70.1)$ & $4(1.3)$ & $1.07 \pm 0.84$ \\
\hline Day $7^{a}$ & $184(58.6)$ & $129(41.1)$ & $1(0.3)$ & $0.49 \pm 0.52$ \\
\hline $\operatorname{Max}-L L S^{b}$ & $18(5.7)$ & $174(55.4)$ & $119(37.9)$ & $4.1 \pm 3.17$ \\
\hline
\end{tabular}

LLS, Lake Louise Score.

${ }^{a}$ Some subjects missed the investigation during the follow-up: 7 missed on day $4 ; 17$ missed on day $5 ; 31$ missed on day 6 ; and 44 missed on day 7.

${ }^{b}$ Maximal LLS during the 7-day investigation. 
Table 2. Mean and SD of each continuous factor in acute mountain sickness and non-acute mountain sickness groups

\begin{tabular}{|c|c|c|c|c|c|}
\hline \multirow[b]{2}{*}{ Factor } & \multirow[b]{2}{*}{ Mean } & \multirow[b]{2}{*}{$S D$} & \multirow[b]{2}{*}{$P$ value $^{a}$} & \multicolumn{2}{|c|}{$\begin{array}{l}95 \% \text { CI for } \\
\text { mean }\end{array}$} \\
\hline & & & & $\begin{array}{l}\text { Lower } \\
\text { bound }\end{array}$ & $\begin{array}{l}\text { Upper } \\
\text { bound }\end{array}$ \\
\hline \multicolumn{6}{|l|}{ Age (year) } \\
\hline Non-AMS & 20.25 & 1.83 & .414 & & \\
\hline AMS & 20.08 & 1.62 & & & \\
\hline Total & 20.18 & 1.75 & & & \\
\hline \multicolumn{6}{|l|}{ BMI $\left(\mathrm{kg} / \mathrm{m}^{2}\right)$} \\
\hline Non-AMS & 21.47 & 2.27 & .529 & & \\
\hline AMS & 21.31 & 1.90 & & & \\
\hline Total & 21.41 & 2.14 & & & \\
\hline \multicolumn{6}{|l|}{ VC (L) } \\
\hline Non-AMS & 3.26 & 0.58 & .054 & & \\
\hline AMS & 3.13 & 0.59 & & & \\
\hline Total & 3.21 & 0.59 & & & \\
\hline \multicolumn{6}{|l|}{ FVC (L) } \\
\hline Non-AMS & 2.81 & 0.63 & .246 & & \\
\hline AMS & 2.73 & 0.57 & & & \\
\hline Total & 2.78 & 0.60 & & & \\
\hline \multicolumn{6}{|l|}{$\mathrm{FE}_{\mathrm{NO}}(\mathrm{ppb})$} \\
\hline Non-AMS & 14.74 & 10.53 & .003 & 13.25 & 16.23 \\
\hline AMS & 11.03 & 10.77 & & 9.07 & 12.98 \\
\hline Total & 13.33 & 10.75 & & & \\
\hline \multicolumn{6}{|l|}{$\mathrm{FE}_{\mathrm{CO}}(\mathrm{ppm})$} \\
\hline Non-AMS & 6.10 & 4.34 & $<.001$ & 5.49 & 6.72 \\
\hline AMS & 4.39 & 3.46 & & 3.76 & 5.02 \\
\hline Total & 5.45 & 4.11 & & & \\
\hline
\end{tabular}

AMS, acute mountain sickness; BMI, body mass index; $\mathrm{FE}_{\mathrm{CO}}$, fraction exhaled carbon monoxide; $\mathrm{FE}_{\mathrm{NO}}$, fraction exhaled nitric oxide; FVC, forced vital capacity; VC, vital capacity.

${ }^{a}$ Student's $t$ test for each factor.

3, although drinking behavior did not differ between groups, the AMS group had a significantly lower smoking rate than the non-AMS group. Table 4 shows that the

Table 3. Drinking and smoking behaviors in acute mountain sickness and non-acute mountain sickness groups

\begin{tabular}{lrrrr}
\hline & Non-AMS & AMS & Total & P value \\
\hline Drinking & & & & \\
$\quad$ No & 143 & 83 & 226 & .519 \\
$\quad$ Yes & 52 & 36 & 88 & \\
Smoking & & & & \\
$\quad$ No & 93 & 83 & 176 & $<.001$ \\
$\quad$ Yes & 102 & 36 & 138 & \\
Total & 195 & 119 & 314 & \\
\hline
\end{tabular}

AMS, acute mountain sickness.

${ }^{a} \chi^{2}$ test for each factor.
Table 4. Factors affecting fractions of exhaled nitric oxide and carbon monoxide in smoking and nonsmoking groups

\begin{tabular}{lrrr}
\hline \multicolumn{1}{c}{ Factor } & Mean & SD & P value \\
\hline $\mathrm{FE}_{\mathrm{CO}}$ (ppm) & & & \\
$\quad$ Non smoking & 2.65 & 1.27 & $<.001$ \\
$\quad$ Smoking & 9.03 & 3.69 & \\
$\quad$ Total & 5.45 & 4.11 & \\
$\mathrm{FE}_{\mathrm{NO}}(\mathrm{ppb})$ & & & \\
$\quad$ Non smoking & 14.76 & 12.11 & $<.001$ \\
Smoking & 11.51 & 8.42 & \\
$\quad$ Total & 13.33 & 10.75 & \\
\hline
\end{tabular}

$\mathrm{FE}_{\mathrm{CO}}$, fraction exhaled carbon monoxide; $\mathrm{FE}_{\mathrm{NO}}$, fraction exhaled nitric oxide.

${ }^{a}$ Student's $t$ test for each factor.

smoking group had a significantly higher $\mathrm{FE}_{\mathrm{CO}}$ value and a lower $\mathrm{FE}_{\mathrm{NO}}$ value than the nonsmoking group $(P<$ $.001)$.

The correlation coefficients between LLS (daily LLS and max-LLS) and the other variables and those among the other variables were analyzed. Negative correlations with max-LLS and most-day LLSs were observed for $\mathrm{VC}, \mathrm{FVC}, \mathrm{FE}_{\mathrm{NO}}, \mathrm{FE}_{\mathrm{CO}}$, and smoking history. In addition, $\mathrm{FE}_{\mathrm{CO}}$ and smoking rates negatively correlated with $\mathrm{FE}_{\mathrm{NO}}$ but positively correlated with $\mathrm{BMI}$. The $\mathrm{FE}_{\mathrm{CO}}$ and smoking behavior, $\mathrm{VC}$, and $\mathrm{FVC}$ were also strongly positively correlated $(\mathrm{r}=.831, P<.001$ and $\mathrm{r}=.746, P<.001$, respectively). Therefore, $\mathrm{FE}_{\mathrm{CO}}$ was strongly correlated with the variables associated with smoking behavior. Smoking behavior was thereby excluded as a variable from further regression analyses, and FVC was excluded as well.

The separated linear regressions showed that both $\mathrm{FE}_{\mathrm{NO}}$ and $\mathrm{FE}_{\mathrm{CO}}$ were significantly associated with LLSs on days 1 through 6 and with the max-LLS. The controlled variables (age, BMI, and drinking behavior) were not significantly associated with AMS in either separated model (data not shown), although VC was significantly associated with AMS in most separated models. The integrated and separated model analyses showed similar results. The VIF values demonstrated an acceptable collinearity (VIF $<0.5)$.

In the separated and integrated logistic regression models, $\mathrm{FE}_{\mathrm{NO}}$ and $\mathrm{FE}_{\mathrm{CO}}$ were significantly negatively associated with LLS score, whereas VC was only significant in separated model II $\left(\mathrm{FE}_{\mathrm{CO}}\right.$ model). Other controlled variables were not significant in any model (Table 5). The Hosmer-Lemeshow test indicated that the models fit well. The ROC curves are depicted in Figure 2, and the results of the ROC curve analyses are shown in Table 6. The results suggested that the areas under the ROC 
Table 5. Separated and integrated logistic regression models to test the predictive value of fractions of exhaled nitric oxide and carbon monoxide, adjusted for age, body mass index, vital capacity, and drinking behavior $(n=314)$

\begin{tabular}{llcccc}
\hline \multicolumn{1}{c}{ Models } & Variable $^{a}$ & $\beta$ & OR $(95 \%$ CI $)$ & P value of $\beta$ & P value of H-L $L^{b}$ \\
\hline \multirow{2}{*}{ Separated models I } & $\mathrm{FE}_{\mathrm{NO}}$ & -1.497 & $0.224(0.113,0.442)$ & $<.001$ & .131 \\
& $\mathrm{VC}$ & -0.319 & $0.727(0.480,1.100)$ & $<.001$ & .040 \\
Separated models II & $\mathrm{FE}_{\mathrm{CO}}$ & -1.705 & $0.182(0.075,0.443)$ & $<.001$ & .526 \\
& $\mathrm{VC}$ & -0.436 & $0.647(0.427,0.981)$ & .001 & .708 \\
Integrated model & $\mathrm{FE}_{\mathrm{NO}}$ & -1.831 & $0.160(0.078,0.330)$ & .072 \\
& $\mathrm{FE}_{\mathrm{CO}}$ & -2.238 & $0.107(0.040,0.285)$ & & \\
& $\mathrm{VC}$ & -0.398 & $0.671(0.435,1.036)$ & & \\
\hline
\end{tabular}

$\mathrm{FE}_{\mathrm{CO}}$, fraction exhaled carbon monoxide; $\mathrm{FE}_{\mathrm{NO}}$, fraction exhaled nitric oxide; OR, odds ratio; $\mathrm{VC}$, vital capacity.

${ }^{a}$ Values for $\mathrm{FE}_{\mathrm{NO}}$ and $\mathrm{FE}_{\mathrm{CO}}$ are $\log$ transformed.

${ }^{b}$ Hosmer-Lemeshow test.

curve were larger than 0.5 , and the 2 separated model AUCs were not significantly different. However, the integrated model AUC was significantly larger than the 2 separated models. According to Hosmer and Lemeshow's suggestion regarding AUC, the separated models had poor discrimination, whereas the integrated model had acceptable discrimination ${ }^{30}$; the best cutoff value was 0.406 (positive predictive value was $59.2 \%$ and negative predictive value was $76.2 \%$ ). However, all of the model prediction values were low.

\section{Discussion}

The results of the statistical analysis suggest that higher $\mathrm{FE}_{\mathrm{NO}}$ and $\mathrm{FE}_{\mathrm{CO}}$ before ascent to a high altitude are protective factors for AMS. The daily LLS and the AMS

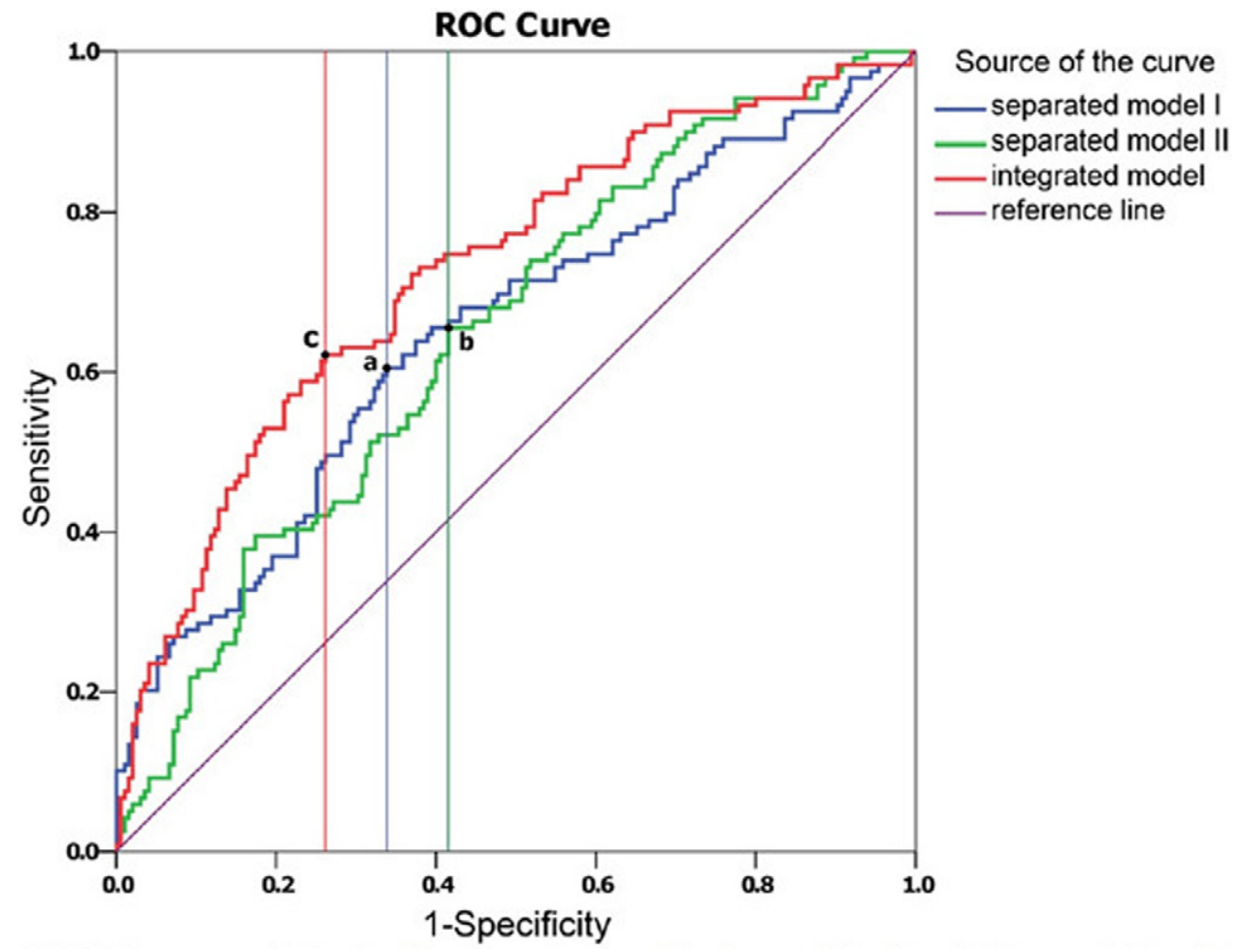

Figure 2. Receiver operating characteristic curves of the logistic regression models (a: cutoff value $=0.374$, sensitivity $=60.5 \%$, specificity $=66.2 \%$; b: cutoff value $=0.370$, sensitivity $=65.6 \%$, specificity $=58.5 \%$; : cutoff value $=0.406$, sensitivity $=62.2 \%$, specificity $=73.9 \%$ ). Separated model I (blue line): the logistic regression models to test the predictive value of the fraction of exhaled nitric oxide; separated model II (green line): the logistic regression models to test the predictive value of the fraction of exhaled carbon monoxide; integrated model (red line): the logistic regression models to test the predictive value of the fractions of exhaled nitric oxide and carbon monoxide). 
Table 6. Receiver operating characteristic curve analyses for logistic regression models

\begin{tabular}{lccc}
\hline \multicolumn{1}{c}{ Item } & \multicolumn{1}{c}{ Model } \\
\cline { 2 - 4 } & Separated models I & Separated models II & Integrated model \\
\hline Sample size & 314 & 314 & 314 \\
AUC with 95\% CI & $0.651(0.587,0.715)$ & $0.646(0.584,0.707)$ & $0.726(0.667,0.784)$ \\
$Z$ statistic vs. AUC $=0.5$ & $4.641(P<.001)$ & $4.626(P<.001)$ & $7.595(P<.001)$ \\
$Z$ statistic vs. ROC I & - & $0.126(P=.900)$ & $3.123(P=.002)$ \\
$Z$ statistic vs. ROC II & - & - & $2.826(P=.005)$ \\
Cutoff value & 0.374 & 0.370 & 0.406 \\
Sensitivity (\%) with 95\% CI & $60.5(51.1,69.3)$ & $58.6(56.3,74.0)$ & $62.2(52.8,70.9)$ \\
Specificity (\%) with 95\% CI & $66.2(59.0,72.8)$ & $49.1(41.1,57.1)$ & $73.9(67.1,79.9)$ \\
PPV (\%) with 95\% CI & $52.2(43.5,60.7)$ & $73.5(65.9,80.3)$ & $59.2(50.1,67.9)$ \\
NPV (\%) with 95\% CI & $73.3(66.1,79.7)$ & $76.2(69.5,82.1)$ \\
\hline
\end{tabular}

AUC, area under the curve; NPV, negative predictive value; PPV, positive predictive value; ROC, receiver operating characteristic.

${ }^{a}$ ROC curve of separated models I.

${ }^{b}$ ROC curve of separated models II.

diagnosis results are closely associated with the 2 exhaled gases. As for the controlling factors, age, BMI, and drinking behavior are not significantly associated with AMS, similar to the previous reports. ${ }^{3,10,18}$ Finally, VC is negatively correlated with AMS, which has also been previously reported. ${ }^{31}$

Pulmonary NO may play an important role in the physiological response to acute high altitude hypoxia. ${ }^{12}$ Some studies have demonstrated the importance of pulmonary vascular endothelial and alveolar epithelial NO synthesis in the regulation of pulmonary vascular responsiveness to high altitude exposure, ${ }^{32}$ and that a lower $\mathrm{FE}_{\mathrm{NO}}$ likely weakens airway and vascular smooth muscle relaxation and the regulation of ventilation-perfusion matching. ${ }^{13}$ In addition, poor gas exchange in the lungs could also contribute to AMS. Our results also suggest that LLS and the AMS diagnosis results are closely associated with the $\mathrm{FE}_{\mathrm{NO}}$ before ascent to high altitude. Therefore, a lower $\mathrm{FE}_{\mathrm{NO}}$ may hinder proper acclimatization to altitude, increasing the probability of AMS. Certainly, data from studies on the effect of hypoxia on exhaled NO are also inconsistent. Brown et $\mathrm{al}^{12}$ have shown that exhaled NO had no predictive value for AMS. We think these conflicts might result from differences in procedures, experimental protocols, exposure times, and samples.

The latest $\mathrm{FE}_{\mathrm{NO}}$ standard procedure to determine expired NO is defined by the ATS and the ERS, and the ATS/ERS method has primarily been designed for use at sea level or at moderate altitude. ${ }^{27,33}$ Some commercially available instruments for these standardized measurements have been described. ${ }^{34}$ Study has also shown that $\mathrm{FE}_{\mathrm{NO}}$ values measured with NObreath are reproducible and in good agreement with those obtained by NIOX
MINO and Logan, indicating that NObreath is suitable for use in practice. ${ }^{14}$ Therefore, the NObreath instrument used to measure $\mathrm{FE}_{\mathrm{NO}}$ value can be adopted in our study.

Measured $\mathrm{FE}_{\mathrm{CO}}$ is closely linked to active and passive smoking, traffic exhaust, and industrial smoke, whereas the endogenous $\mathrm{CO}$ production is of relatively minor importance. Considering the environment of the training base, traffic exhaust and industrial smoke can be excluded. Additionally, because the LOD of the device is 1 to $250 \mathrm{ppm}$, which is greater than the endogenous $\mathrm{CO}$ level (less than 1 $\mathrm{ppm}),{ }^{35}$ the $\mathrm{FE}_{\mathrm{CO}}$ only represents tobacco consumption (including passive) in this study. The $\mathrm{FE}_{\mathrm{CO}}$ values obtained by this method may be more accurate than those obtained from the self-report of smoking behavior.

The results indicate that smoking behavior at low elevations significantly decreases the risk of AMS when one travels to a high altitude. However, this does not mean that smoking is entirely beneficial for decreasing AMS. Some studies have shown that smokers exhale significantly less $\mathrm{NO}$ than do healthy volunteers. ${ }^{36,37}$ In our study, the $\mathrm{FE}_{\mathrm{NO}}$ values of smokers are significantly lower than those of nonsmokers $(P<.001$; Table 4$)$. Therefore, the $\mathrm{FE}_{\mathrm{CO}}$ value was negatively correlated with max-LLS and most-day LLSs, but it did not indicate that the higher the $\mathrm{FE}_{\mathrm{CO}}$ value is, the lower the risk of AMS would be. We think the effect of smoking is bidirectional. In some range, $\mathrm{FE}_{\mathrm{CO}}$ has a protective role for AMS. Smoking during the ascent is also very harmful; indeed, smoking and drinking were forbidden in this operation.

The results of the logistic regression analysis further validate the relationship between $\mathrm{AMS}$ and $\mathrm{FE}_{\mathrm{NO}}$ and $\mathrm{FE}_{\mathrm{CO}}$ before high altitude exposure. In addition, the ROC analysis suggests that both exhaled gases have independent modest predictive value for AMS susceptibility. If they are com- 
bined into one model, the significance of the predictive value and the goodness-of-fit for AMS prediction will be increased. However, the combined predictive value is still insufficient. This may be because the mechanism of AMS development is very complex and cannot be explained by 2 exhaled gases alone. This implies that studies on other variables are needed in the future to better predict AMS.

The results showed the 95\% CI for the mean $\mathrm{FE}_{\mathrm{NO}}$ and $\mathrm{FE}_{\mathrm{CO}}$ values in non-AMS and AMS groups before the ascent to a high altitude. Whether $95 \% \mathrm{CI}$ can be used as the criterion for diagnosing AMS susceptibility needs further validation. Because $\mathrm{FE}_{\mathrm{NO}}$ and $\mathrm{FE}_{\mathrm{CO}}$ values before high altitude exposure are related to AMS susceptibility, in future work we will consider researching the reference ranges of $\mathrm{FE}_{\mathrm{NO}}$ and $\mathrm{FE}_{\mathrm{CO}}$ for AMS susceptibility in the healthy population based on large samples and stricter tests to accurately predict AMS. We expect to achieve the prediction of AMS susceptibility by comparing the measured value and the value of $\mathrm{FE}_{\mathrm{NO}}$ and $\mathrm{FE}_{\mathrm{CO}}$ in the reference range.

This study is, to our knowledge, the first to focus on the relationship between AMS and exhaled gases $\left(\mathrm{FE}_{\mathrm{NO}}\right.$ and $\mathrm{FE}_{\mathrm{CO}}$ ) before a group of Chinese lowlander servicemen's ascent to a highland $(>2500 \mathrm{~m})$. In our study, the relationship between the exhaled gases and AMS is assessed based on a large sample size. As a prospective study, the investigation was well conducted and truly reflected AMS in detail; the observers accompanied the subjects during the full journey and recorded the daily LLS of each subject according to both self-reported and clinical signs. In addition, thanks to the nature of the military organization and routine military operation, we obtained reliable and comprehensive background information, high response rate, and full cooperation, which enhance the study quality.

\section{LIMITATIONS}

Several limitations exist in the study design and should be considered when generalizing our findings to other populations or conditions. First, in this study, occupation, diet, and physical load at a high altitude were negligible because everyone experienced the same condition. Therefore, the identifiable risk factors for AMS among such a specialized population are limited. Second, the Operating Manual of the Micro+ Smokerlyzer monitor points out that subjects with $\mathrm{FE}_{\mathrm{CO}}$ values $>6$ are considered to be smokers, we think the $\mathrm{FE}_{\mathrm{CO}}$ value can quantitatively reflect the smoking behavior of subjects, and studies also showed that smoking is positively associated with hemoglobin concentration, ${ }^{38}$ so we did not consider measuring the hemoglobin concentrations. Third, because of the large number of subjects and the routine operations, we could not collect LLS in the morning. Moreover, because AMS cases were diagnosed by different observers over the course of almost 4 days, bias is inevitable and uncontrollable. However, the sample size is large enough to at least partially limit this confounding effect.

\section{Conclusions}

In conclusion, the concentrations of $\mathrm{FE}_{\mathrm{NO}}$ and $\mathrm{FE}_{\mathrm{CO}}$ before exposure to a high altitude correlate with AMS and may offer a new method for predicting AMS susceptibility. However, the predictive value of measurements of $\mathrm{FE}_{\mathrm{NO}}$ and $\mathrm{FE}_{\mathrm{CO}}$ made before high altitude exposure still awaits validation of further studies.

\section{Acknowledgments}

We are grateful to the medical department of the highland military units and their staff for providing great assistance in this study. We also thank the volunteers for participating in this study. We would like to thank Miss Xie-Wan Chen and Ms Xiao-Qing Zhan for a critical reading of the manuscript and kindly giving precious advice.

This study was supported by 973 project of China (2012CB518201). This work was supported by a research grant from the Chinese National Science Support Project (2009BAI85B01).

\section{References}

1. Moore LG, Harrison GL, McCullough RE, et al. Low acute hypoxic ventilatory response and hypoxic depression in acute altitude sickness. J Appl Physiol. 1986;60: 1407-1412.

2. Rathat C, Richalet JP, Herry JP, Larmignat P. Detection of high-risk subjects for high altitude diseases. Int J Sports Med. 1992;13(suppl 1):S76-S78.

3. Gaillard S, Dellasanta P, Loutan L, Kayser B. Awareness, prevalence, medication use, and risk factors of acute mountain sickness in tourists trekking around the Annapurnas in Nepal: a 12-year follow-up. High Alt Med Biol. 2004;5: 410-419.

4. Graham J, Potyk D. Age and acute mountain sickness: examining the data. J Am Geriatr Soc. 2005;53:735.

5. Karinen HM, Peltonen JE, Kähönen M, Tikkanen HO. Prediction of acute mountain sickness by monitoring arterial oxygen saturation during ascent. High Alt Med Biol. 2010;11:325-332.

6. King AB, Robinson SM. Ventilation response to hypoxia and acute mountain sickness. Aerosp Med. 1972;43: 419-421.

7. Hohenhaus E, Paul A, McCullough RE, Kücherer $\mathrm{H}$, Bärtsch P. Ventilatory and pulmonary vascular response to 
hypoxia and susceptibility to high altitude pulmonary oedema. Eur Respir J. 1995;8:1825-1833.

8. Bärtsch P, Swenson ER, Paul A, Jülg B, Hohenhaus E. Hypoxic ventilatory response, ventilation, gas exchange, and fluid balance in acute mountain sickness. High Alt Med Biol. 2002;3:361-376.

9. Milledge JS, Beeley JM, Broome J, Luff N, Pelling M, Smith D. Acute mountain sickness susceptibility, fitness and hypoxic ventilatory response. Eur Respir J. 1991;4: 1000-1003.

10. Ziaee V, Yunesian M, Ahmadinejad Z, et al. Acute mountain sickness in Iranian trekkers around Mount Damavand (5671 m) in Iran. Wilderness Environ Med. 2003;14: 214-219.

11. Macinnis MJ, Koehle MS, Rupert JL. Evidence for a genetic basis for altitude illness: 2010 update. High Alt Med Biol. 2010;11:349-368.

12. Brown DE, Beall CM, Strohl KP, Mills PS. Exhaled nitric oxide decreases upon acute exposure to high-altitude hypoxia. Am J Hum Biol. 2006;18:196-202.

13. Özkan M, Dweik RA. Nitric oxide and airway reactivity. Clin Pulm Med. 2001;8:199-206.

14. Antus B, Horvath I, Barta I. Assessment of exhaled nitric oxide by a new hand-held device. Respir Med. 2010;104: 1377-1380.

15. Droma Y, Hanaoka M, Ota M, et al. Positive association of the endothelial nitric oxide synthase gene polymorphisms with high-altitude pulmonary edema. Circulation. 2002; 106:826-830.

16. Macinnis MJ, Carter EA, Koehle MS, Rupert JL. Exhaled nitric oxide is associated with acute mountain sickness susceptibility during exposure to normobaric hypoxia. Respir Physiol Neurobiol. 2012;180:40-44.

17. Scherrer U, Turini P, Thalmann S, et al. Pulmonary hypertension in high-altitude dwellers: novel mechanisms, unsuspected predisposing factors. In: Roach RC, Wagner PD, Hackett PH, eds. Hypoxia and Exercise.New York, NY: Springer Science+Business Media, LLC; 2006:277-292.

18. Schneider M, Bernasch D, Weymann J, Holle R, Bartsch P. Acute mountain sickness: influence of susceptibility, preexposure, and ascent rate. Med Sci Sports Exerc. 2002;34: 1886-1891.

19. Wada K, Mizuguchi Y, Wada Y, Ohno Y, Iino Y. Hyperlipidaemia, lack of sleep and smoking as risk factors for proteinuria among high altitude mountain trekkers. $\mathrm{Ne}$ phrology (Carlton). 2006;11:131-136.

20. Kunze U, Böhm G, Ferstl F, Groman E. Assessing smoking behaviour among medical students by the measurement of expired carbon monoxide (CO). Wien Med Wochenschr. 2009;159:14-16.

21. Chatrchaiwiwatana S, Ratanasiri A. Exhaled carbon monoxide level and smoking status in urban Khon Kaen adults. J Med Assoc Thai. 2008;91:1669-1676.

22. Gajdócsy R, Horváth I. Exhaled carbon monoxide in airway diseases: from research findings to clinical relevance. J Breath Res. 2010;4:047102.
23. Palmer BF. Physiology and pathophysiology with ascent to altitude. Am J Med Sci. 2010;340:69-77.

24. Ignarro LJ. Nitric oxide-a unique endogenous signaling molecule in vascular biology. Biosci Rep. 1999;19:51-71.

25. Prabhakar NR. Gases as chemical messengers in the carotid body. Role of nitric oxide and carbon monoxide in chemoreception. Adv Exp Med Biol. 1995;393:309-312.

26. Chapman JT, Choi AM. Exhaled monoxides as a pulmonary function test: use of exhaled nitric oxide and carbon monoxide. Clin Chest Med. 2001;22:817-836.

27. American Thoracic Society; European Respiratory Society. ATS/ERS recommendations for standardized procedures for the online and offline measurement of exhaled lower respiratory nitric oxide and nasal nitric oxide, 2005. Am J Respir Crit Care Med. 2005;171:912-930.

28. Roach RC, Bartsch P, Hackett PH, Oelz O. The Lake Louise Acute Mountain Sickness scoring system. In: Sutton JR, Houston CS, Coates G, eds. Hypoxia and Molecular Medicine. Burlington, VT: Queen City Press; 1993: 272-274.

29. Basu M, Sawhney RC, Kumar S, Pal K, Prasad R, Selvamurthy W. Glucocorticoids as prophylaxis against acute mountain sickness. Clin Endocrinol (Oxf). 2002;57: 761-767.

30. Hilgers RA. Distribution-free confidence bounds for ROC curves. Methods Inf Med. 1991;30:96-101.

31. Hackett PH, Rennie D, Hofmeister SE, Grover RF, Grover EB, Reeves JT. Fluid retention and relative hypoventilation in acute mountain sickness. Respiration. 1982;43:321-329.

32. Blitzer ML, Loh E, Roddy MA, Stamler JS, Creager MA. Endothelium-derived nitric oxide regulates systemic and pulmonary vascular resistance during acute hypoxia in humans. J Am Coll Cardiol. 1996;28:591-596.

33. Hemmingsson T, Linnarsson D. Lower exhaled nitric oxide in hypobaric than in normobaric acute hypoxia. Respir Physiol Neurobiol. 2009;169:74-77.

34. Hemmingsson T, Linnarsson D, Gambert R. Novel handheld device for exhaled nitric oxide-analysis in research and clinical applications. J Clin Monit Comput. 2004;18: 379-387.

35. Aberg AM, Sojka BN, Winsö O, Abrahamsson P, Johansson G, Larsson JE. Carbon monoxide concentration in donated blood: relation to cigarette smoking and other sources. Transfusion. 2009;49:347-353.

36. Schilling J, Holzer P, Guggenbach M, Gyurech D, Marathia K, Geroulanos G. Reduced endogenous nitric oxide in the exhaled air of smokers and hypertensives. Eur Respir J. 1994;7:467-471.

37. Kharitonov SA, Robbins RA, Yates D, Keatings V, Barnes PJ. Acute and chronic effects of cigarette smoking on exhaled nitric oxide. Am J Respir Crit Care Med. 1995; 152:609-612.

38. Nordenberg D, Yip R, Binkin NJ. The effect of cigarette smoking on hemoglobin levels and anemia screening. JAMA. 1990;264:1556-1559. 